\title{
Acute myeloid leukemia and myelodysplastic syndromes related to topoisomerase type 2 inhibitor
}

INSERM

\section{Source}

INSERM. (1999). Orphanet: an online rare disease and orphan drug data base. Acute myeloid leukemia and myelodysplastic syndromes related to topoisomerase type 2 inhibitor. ORPHA:102381

Acute myeloid leukemia and myelodysplastic syndromes related to topoisomerase type 2 inhibitor represent a subgroup of therapy-related myeloid neoplasms (t-MN), associated with treatment of an unrelated neoplastic disease with cytotoxic agents, like etoposid, doxorubicin, daunorubicin and others. The neoplastic cells often show rearrangements involving the mixed lineage leukemia gene at $11 \mathrm{q} 23$. This subgroup of t-MN is typically associated with overt leukemia, without preceding myelodysplastic syndrome, developing 2-3 years after exposure, presenting with non-specific symptoms related to ineffective hematopoesis (fatigue, bleeding and bruising, recurrent infections, bone pain) and/or extramedullary site involvement. 